\title{
Review \\ Progesterone receptors - animal models and cell signaling in breast cancer The role of oestrogen and progesterone receptors in human mammary development and tumorigenesis
}

\author{
Elizabeth Anderson
}

Tumour Biochemistry Laboratory, Christie Hospital NHS Trust, Manchester, UK

Correspondence: Elizabeth Anderson, PhD, Tumour Biochemistry Laboratory, Clinical Research Department, Christie Hospital NHS Trust, Wilmslow Road, Manchester M20 4BX, UK. Tel: +44 161446 3221; fax: +44 161446 3211; e-mail: eanderson@picr.man.ac.uk

\begin{abstract}
A relatively small number of cells in the normal human mammary gland express receptors for oestrogen and progesterone (ER and PR), and there is almost complete dissociation between steroid receptor expression and proliferation. Increased expression of the ER alpha (ER $\alpha)$ and loss of the inverse relationship between receptor expression and proliferation occur at the very earliest stages of tumorigenesis, implying that dysregulation of ER $\alpha$ expression contributes to breast tumour formation. There is evidence also for alterations in the ratio between the two PR isoforms in premalignant breast lesions. Elucidation of the factors mediating the effects of oestradiol and progesterone on development of the normal breast and of the mechanisms by which expression of the ER $\alpha$ and the PR isoforms is controlled could identify new targets for breast cancer prevention and improved prediction of breast cancer risk.
\end{abstract}

Keywords: breast tumours, normal mammary epithelium, oestrogen receptor, progesterone receptor

\section{Introduction}

The human mammary epithelium is the tissue from which most breast tumours arise. Understanding how processes such as proliferation and differentiation of the epithelium are controlled by the ovarian steroids oestradiol and progesterone may lead to an increased understanding of the carcinogenic process. The present article reviews some of what is known about the involvement of the receptors for oestradiol and progesterone in the normal mammary gland and in tumorigenesis.

\section{Structure of the human mammary gland}

The mammary gland is not completely formed at birth, but begins to develop in early puberty when the primitive ductal structures enlarge and branch [1]. Once ovulatory menstrual cycles have begun, branching of the ductal system becomes more complex and lobular structures form at the ends of the terminal ducts to produce terminal ductal lobular units (TDLUs), which become more complex with successive menstrual cycles. During early pregnancy, there is another burst of activity in which the ductal trees expand further and the number of ductules within the TDLUs increases greatly. These ductules differentiate to synthesise and secrete milk in late pregnancy and subsequent lactation.

The entire ductal system of the human mammary gland is lined by a continuous layer of luminal epithelial cells that is, in turn, surrounded by a layer of myoepithelial cells. These myoepithelial cells are in direct contact with the basement membrane, and the TDLUs are surrounded by delimiting fibroblasts and embedded in a specialised intralobular 
stroma. Histological studies have shown that most human breast tumours appear to be derived from TDLUs and have morphological characteristics of luminal epithelial cells (reviewed in [2]). Moreover, most human breast tumours retain the biochemical features of luminal cells in that they express the appropriate cytokeratins and membrane antigens such as MUC-1 [2]. Human tumours also contain receptors for oestradiol and progesterone that, in the normal breast, are expressed only in the luminal epithelial cell compartment. Luminal epithelial cells must therefore be regarded as the primary targets for malignant transformation and subsequent tumour formation.

The process of breast tumorigenesis is thought to result from a 'benign to malignant' progression in which the accumulation of multiple genetic changes allows evolution from normal breast epithelium through benign proliferative lesions to atypical proliferative lesions, and then to carcinoma in situ and frankly invasive tumours. This progression is elegantly reviewed by Allred and colleagues [3], who report that the lesions associated with the greatest risk of invasive breast cancer are hyperplasia of usual type, atypical ductal hyperplasia, ductal carcinoma in situ (DCIS) and lobular carcinoma in situ.

\section{Ovarian steroids, breast development and tumorigenesis}

The clinical and epidemiological evidence for an obligate role of oestrogen in human mammary gland development and tumorigenesis is considerable. There is complete failure of breast development in the absence of intact ovarian function, and oestradiol-replacement therapy is necessary to induce breast development [4]. Increased exposure to the fluctuating levels of oestradiol of the menstrual cycle through early menarche, late menopause or a late, first, full-term pregnancy increases breast cancer risk, as does use of exogenous oestrogens in the form of the oral contraceptive pill or hormone replacement therapy [5]. More compellingly, treatment with antioestrogens reduces the incidence of breast cancer in high-risk women [6]. The obligate role for oestradiol in mammary gland development and tumour formation has been confirmed in studies on mice where the gene for the $E R \alpha$ has been knocked out [7]. The mammary glands in these ER $\alpha$ knockout mice comprise rudimentary ducts confined to the nipple area, which cannot be induced to develop further with oestradiol treatment and which are resistant to malignant transformation following transduction with oncogenes.

There is far less evidence for a role of progesterone in human breast development. Studies on mouse models in which the PR has been knocked out suggest that, whereas oestradiol stimulates ductal elongation and PR expression, progesterone induces lobuloalveolar develop- a similar role in the human breast and stimulates TDLU formation and expansion during puberty and pregnancy. As far as is known this has never been demonstrated, although this might be because it is almost impossible to study human breast tissue at these stages of development. As far as a role for progesterone in breast tumorigenesis is concerned, there are now some data suggesting that exogenous progestins taken in the form of combined hormone replacement therapy increase the risk of postmenopausal breast cancer to a greater extent than use of oestrogen replacement therapy alone $[9,10]$.

\section{Effects of oestrogen and progesterone are mediated by the ER and by the PR}

Steroid hormones such as oestradiol and progesterone are lipophilic and they enter cells and their nuclei primarily by diffusing through the plasma and nuclear membranes. Once in the nucleus, the steroids encounter proteins known as receptors because they bind their cognate ligands with high affinity and specificity. There are two receptors for oestradiol, the ER $\alpha$ and the ER $\beta$. Both these ERs are members of the steroid/thyroid hormone nuclear receptor superfamily and both may be described as ligand-dependent nuclear transcription factors. The ER proteins have the modular structure that typifies the nuclear receptor superfamily, which includes domains that mediate binding to ligands and to DNA. Although the two ERs are homologous in their DNA-binding and steroidbinding domains, the ER $\beta$ gene is smaller, it has a different chromosomal location and it encodes a shorter protein $[11,12]$. The distinctly different but overlapping tissue distribution of the ER $\beta$ compared with the ER $\alpha$ suggests that it might mediate some of the non-classical effects of oestrogens and anti-oestrogens. Alternatively, the results of experimental studies suggest that the ER $\beta$ might interact with and negatively modulate the actions of the ER $\alpha$ [13].

Progesterone also has two receptors, PRA and PRB. Unlike the ERs, however, these two receptors are transcribed from the same gene via alternative promoter usage. PRB is longer than PRA as it contains an additional 164 amino acids at its $\mathrm{N}$-terminal, but otherwise the two proteins are identical [14]. PRA and PRB also are members of the steroid/thyroid hormone nuclear receptor superfamily, and they function as ligand-dependent nuclear transcription factors. It has been suggested that PRB is the major activator of gene transcription and that PRA is a repressor of PRB activity [15]. However, more recent studies on breast cancer cells engineered to express either PRA or PRB alone [16] or on mice in which the isoforms have been selectively deleted [17] suggest that PRA as well as PRB can activate gene transcription. Moreover, the two isoforms can be differentiated in terms of the profile of genes that they can activate and by the fact that PRB, but not PRA, mediates the effects of progesterone on mouse mammary gland development [17]. 


\section{ER and PR expression in normal human breast}

Most data on ER and PR expression in the normal human breast have been obtained in the course of studies on tissue from adult women who are neither pregnant nor lactating. These studies show that ER $\alpha$ is expressed in approximately $15-30 \%$ of luminal epithelial cells and not at all in any of the other cell types within the human breast [18]. Studies on the expression of ER $\beta$ in either normal or malignant human breast epithelium have been hampered by a lack of antibodies that can reliably detect the protein in sections of formalin-fixed, paraffin-embedded tissue. Such antibodies have recently been developed [19], however, and initial studies indicate that the ER $\beta$ is expressed in most luminal epithelial and myoepithelial cells, as well as being detectable in fibroblasts and other stromal cells within the normal human breast [20]. Unfortunately, this widespread distribution is not very informative as regards the function of the ER $\beta$ in the normal breast. The results of studies on mice in which the ER $\beta$ has been deleted are similarly uninformative as the mammary glands develop normally in these mice and they appear to have no difficulty in nursing their young [21]. These data thus suggest that, despite its more restricted pattern of expression, the ER $\alpha$ is the key mediator of oestradiol action in the normal mammary gland and suggest that further studies are required to establish the role of ER $\beta$.

Most of the investigations where immunohistochemistry was used to determine the level and distribution of PR expression in the normal human breast were carried out before reagents capable of distinguishing the two isoforms became available. Nevertheless, these studies showed that, like the ER $\alpha$, the PR was present in $15-30 \%$ of luminal epithelial cells and not elsewhere in the breast [18].

Dual-label immunofluorescent techniques have been used to show that all cells expressing the PR also contain the $\mathrm{ER} \alpha$. In contrast, steroid receptor-expressing cells are separate from, but often adjacent to, these labelled with markers of proliferation [18]. This dissociation between steroid receptor expression and proliferation has been confirmed by other groups in both human breast and in rodent mammary glands [22]. The current hypothesis is that oestradiol and/or progesterone controls the proliferative activity of luminal epithelial cells indirectly in a mechanism where the receptor-containing cells act as 'sensors' that secrete positive or negative paracrine and/or juxtacrine growth factors, according to the prevailing oestradiol/progesterone concentrations, to influence the activity of nearby division-competent cells. This would attenuate the sensitivity of the breast epithelium to steroid hormones such that proliferation will occur only when a sufficient concentration of positive growth factors has accumulated. This might be achieved only after prolonged exposure to high levels of steroid and possibly other hormones, as in early pregnancy, and may be a mechanism for preventing excessive proliferative activity at other times.

\section{Relationship between the ER, the PR and proliferation in tumorigenesis}

Increased ER $\alpha$ expression may be one of the very earliest changes occurring in the tumorigenic process. Khan and colleagues [23] have shown increased ER $\alpha$ expression in normal epithelium taken from tumour-bearing breasts. In addition, ER $\alpha$ expression is higher in the breast tissue of women from a population at high risk of breast cancer compared with that in the tissue of Japanese women who have a relatively low risk of the disease [24]. ER $\alpha$ expression is increased at the very earliest stages of ductal hyperplasia and increases still further with increasing atypia, such that most cells in atypical ductal hyperplasias and in DCIS of low and intermediate nuclear grade contain the ER $\alpha[3,25]$. There are fewer ER $\alpha$-positive cells in DCIS of high nuclear grade, but the expression of markers such as c-erbB-2/HER-2 suggests that these lesions form a different pathway to invasive cancer.

As ER $\alpha$ expression increases, the inverse relationship between receptor expression and proliferation becomes dysregulated. There are increasing numbers of cells expressing both the ER $\alpha$ and the Ki67 proliferationassociated antigen with progression toward malignancy, and this is another early change associated with the process of breast tumorigenesis [26]. Interestingly, a proportion of hyperplasias of usual type also contain proliferating ER $\alpha$-positive cells, and it remains to be seen whether these lesions are the ones that progress to invasive tumours. Approximately $70 \%$ of invasive breast carcinomas contain the $\mathrm{ER} \alpha$, and preliminary studies indicate that most of these tumours contain ER $\alpha$-positive, proliferating cells [18]. Clearly, patients whose invasive tumours contain the ER $\alpha$ are suitable for endocrine therapy, but there is no evidence that dysregulation of the relationship between receptor expression and proliferation has any influence on their response. This is in keeping with the suggestion that dysregulation is an important step in early tumorigenesis but is less important at later stages.

There are some data showing that ER $\beta$ expression is downregulated in lesions such as atypical ductal hyperplasia and DCIS when compared with that in normal breast epithelium [27]. The same group has shown that the receptor is inversely correlated with proliferation and that the ratio between the ER $\alpha$ and the ER $\beta$ increases with increasing atypia. This is consistent with the suggestion that the ER $\beta$ negatively modulates the effects of the ER $\alpha$ [27]. The data with regard to ER $\beta$ expression in invasive tumours and its relationship to prognosis or response to endocrine therapy are somewhat contradictory, with some groups reporting that the presence of this receptor is a good prognostic factor and others reporting the reverse [28]. 
There are a few studies on PR expression in premalignant and preinvasive lesions, and these few suggest that expression of the PR also increases with increasing atypia [3]. There is some evidence suggesting that the ratio between PRA and PRB is altered during tumorigenesis, such that PRA predominates [29]. How this can be reconciled with the suggestion that PRA acts as a dominant repressor of the action of PRB and other steroid receptors has yet to be determined, but these data suggest that alteration of the PR isoform ratio also has a role in human breast tumorigenesis. Approximately $60 \%$ of invasive breast carcinomas express PRA and/or PRB, and PR expression is regarded generally as a marker of intact $E R \alpha$ function [3]. Patients whose tumours contain both the $\mathrm{ER} \alpha$ and the PR have the greatest probability of responding to endocrine therapy and have a better prognosis than those whose tumours do not contain steroid receptors. Whether the PR isoform ratio has any bearing on response to endocrine therapy remains to be determined.

\section{Conclusions}

There is almost complete dissociation between steroid receptor (ER $\alpha$ and $P R)$ expression and proliferation in the normal human mammary epithelium, suggesting that the ovarian steroids oestradiol and progesterone control proliferation and development of the mammary gland indirectly via the secretion of paracrine growth factors. This may be one way of attenuating the sensitivity of the normal mammary epithelium to the effects of the ovarian steroids and of ensuring that significant proliferative activity occurs only when it is needed (i.e. during puberty and pregnancy).

Increased ER $\alpha$ expression and loss of the inverse relationship between steroid receptor expression and proliferation occurs at the earliest stages of breast tumour development, implying that dysregulation of ER $\alpha$ expression is an important step in the tumorigenic process. Clearly, enhanced ER $\alpha$ and PR expression would sensitise the premalignant epithelium to the proliferative effects of their cognate ligands, but it remains to be determined whether oestradiol and progesterone continue to drive proliferation by the indirect mechanisms that exist in the normal epithelium or whether an alternative, more direct, pathway has arisen during malignant transformation.

Further studies on the mechanisms by which oestradiol and progesterone control the development of the human breast and breast tumours could lead to the identification of new targets for breast cancer prevention, to improved prediction of invasive breast cancer risk and to early detection of breast tumours.

\section{References}

1. Russo J, Russo $\mathrm{IH}$ : Development of the human mammary gland. In The Mammary Gland. Development, Regulation and Function. Edited by Neville M, Daniel CW. New York: Plenum; 1987:67-93.
2. Anderson E, Clarke RB, Howell A: Estrogen responsiveness and control of normal human breast proliferation. J Mammary Gland Biol Neoplasia 1998, 3:23-35.

3. Allred DC, Mohsin SK, Fuqua SAW: Histological and biological evolution of human premalignant breast disease. Endocr Relat Cancer 2001, 8:47-61.

4. Laron Z, Pauli R, Pertzelan A: Clinical evidence on the role of estrogens in the development of the breasts. Proc R Soc Edinburgh B1 1989, 95:13-22.

5. Key TJA, Pike MC: The role of oestrogens and progestagens in the epidemiology and prevention of breast cancer. Eur J Cancer Clin Oncol 1984, 24:29-43.

6. Fisher B, Costantino JP, Wickerham DL, Redmond CK, Kavanah M, Cronin W, Vogel V, Robidoux A, Dimitrov N, Atkins J, Daly M, Wieand S, Tan-Chiu E, Ford L, Wolmark N: Tamoxifen for prevention of breast cancer: report of the National Surgical Adjuvant Breast and Bowel Project P-1 study. J Natl Cancer Inst 1998, 90:1371-1388.

7. Bocchinfuso WP, Korack KS: Mammary gland development and tumorigenesis in estrogen receptor knock out mice. $J$ Mammary Gland Biol Neoplasia 1997, 2:323-334.

8. Humphreys R, Lydon J, O'Malley B, Rosen J: Use of the PRKO mice to study the role of progesterone in mammary gland development. J Mammary Gland Biol Neoplasia 1997, 2:343354.

9. Ross RK, Paganini-Hill A, Wan PC, Pike MC: Effect of hormone replacement therapy on breast cancer risk: estrogen versus estrogen plus progestin. J Natl Cancer Inst 2000, 92:328-332.

10. Schairer C, Lubin J, Troisi R, Sturgeon S, Brinton L, Hoover R: Menopausal estrogen and estrogen-progestin replacement therapy and breast cancer risk. JAMA 2000, 283:485-491.

11. Kumar V, Green S, Stack G, Berry M, Jin JR, Chambon P: Functional domains of the human estrogen receptor. Cell 1987, 51: 941-951.

12. Enmark E, Pelto-Huikko M, Grandien K, Lagercrantz $S$, Lagercrantz J, Fried G, Nordenskjold M, Gustafsson J-A: Human estrogen receptor $\beta$-gene structure, chromosomal location and expression pattern. J Clin Endocrinol Metab 1997, 82:42584265.

13. Hall J, McDonnell D: The estrogen receptor $\beta$-isoform (ER $\beta)$ of the human estrogen receptor modulates ER $\alpha$ transcriptional activity and is a key regulator of the cellular response to estrogens and antiestrogens. Endocrinology 1999, 140:55665578.

14. Clarke C, Sutherland RL: Progestin regulation of cellular proliferation. Endocr Rev 1990, 11:266-301.

15. Vegeto E, Shahbaz MM, Wen DX, Goldman ME, O'Malley BW, McDonnell DP: Human progesterone receptor A form is a cell and promoter-specific repressor of human progesterone receptor B function. Mol Endocrinol 1993, 7:1244-1255.

16. Richer JK, Jacobsen BM, Manning NG, Abel MG, Wolf DM, Horwitz KB: Differential gene regulation by the two progesterone receptor isoforms in human breast cancer cells. $J$ Biol Chem 2002, 277:5209-5218.

17. Conneely OM, Mulac-Jericevic B, DeMayo F, Lydon JP, O'Malley BW: Reproductive functions of progesterone receptors. Recent Prog Horm Res 2002, 57:339-355.

18. Clarke R, Howell A, Potten C, Anderson E: Dissociation between steroid receptor expression and cell proliferation in the human breast. Cancer Res 1997, 57:4987-4991.

19. Skliris GP, Parkes AT, Limer JL, Burdall SE, Carder PJ, Speirs V: Evaluation of seven oestrogen receptor $\beta$ antibodies for immunohistochemistry, western blotting and flow cytometry in human breast tissue. J Patho/ 2002, 197:155-162.

20. Speirs V, Skliris GP, Burdall SE, Carder PJ: Distinct expression patterns of $E R \alpha$ and $E R \beta$ in normal human mammary gland. J Clin Pathol 2002, 55:371-374.

21. Couse JF, Korach K: Estrogen receptor null mice: what have we learned and where will they lead us? Endocr Rev 1999, 20: 358-417.

22. Russo J, Ao X, Grill C, Russo IH: Pattern of distribution of cells positive for estrogen receptor alpha and progesterone receptor in relation to proliferating cells in the mammary gland. Breast Cancer Res Treat 1999, 53:217-227.

23. Khan SA, Rogers MA, Obando JA, Tamsen A: Estrogen receptor expression of benign epithelium and its association with breast cancer. Cancer Res 1994, 54:993-997. 
24. Lawson JS, Field AS, Champion S, Tran D, Ishikura H, Trichopoulos D: Low oestrogen receptor $\alpha$ expression in normal human breast tissue underlies low breast cancer incidence in Japan. Lancet 1999, 354:1787-1788.

25. Shoker BS, Jarvis C, Sibson DR, Walker C, Sloane JP: Oestrogen receptor expression in the normal and precancerous breast. J Pathol 1999, 188:237-244.

26. Shoker BS, Jarvis C, Clarke RB, Anderson E, Hewlett J, Davies MPA, Sibson DR, Sloane JP: Estrogen receptor positive proliferating cells in the normal and precancerous breast. $\mathrm{Am} J$ Pathol 1999, 155:1811-1815.

27. Roger $P$, Sahla M, Makela S, Gustafsson J-A, Baldet P, Rochefort $\mathrm{H}$ : Decreased expression of estrogen receptor beta protein in proliferative preinvasive mammary tumors. Cancer Res 2001, 61:2537-2541.

28. Speirs V: Oestrogen receptor $\beta$ in breast cancer: good, bad or still too early to tell? J Pathol 2002, 197:143-147.

29. Mote PA, Bartow S, Tran N, Clarke CL: Loss of co-ordinate expression of progesterone receptors $A$ and $B$ is an early event in breast carcinogenesis. Breast Cancer Res Treat 2002, 72:163-172. 